\title{
SALUD, HIGIENE Y EDUCACIÓN. LOS PRIMEROS SANATORIOS MARÍTIMOS INFANTILES EN EL EXTRANJERO
}

\author{
Health, Hygiene and Education. First Children's Maritime Sanatoriums \\ Abroad
}

\author{
Juan Félix Rodríguez PéRez \\ Fundación Sociedad Protectora de los Niños \\ info@protectoraninos.org
}

Fecha de recepción: 25-II-2013

Fecha de aceptación: 03-III-2013

Resumen: En el estudio que presentamos se analiza la importancia que tuvo la divulgación científica de las bondades del clima marino para la cura de diversas enfermedades infantiles. La aplicación práctica del agua y ambiente marino se llevó a cabo a través de sanatorios infantiles y barcos escuelas flotantes. El primer centro se estableció en Inglaterra, expandiéndose durante todo el siglo XIX y primer tercio del XX por toda Europa y América. Francia, Italia y Alemania se destacaron como países al instaurar una amplia red de centros marítimos para niños débiles. Los receptores de este tratamiento fueron niños enfermos o predispuestos de las clases más populares.

El objetivo de reducir las elevadas tasas de mortalidad infantil que se producían y mejorar la salud de los niños pobres se fue alcanzando de forma eficaz y paulatina. La combinación de actividades sanitarias y educativas que recibían los ingresados, se materializaba en el cumplimiento de un horario determinado, en el aprendizaje de un conjunto de normas higiénicas, juegos variados, baños, lectura de cuentos y una enseñanza rudimentaria de la escritura y lectura.

Palabras clave: higiene, niños, sanatorios, infancia, educación.

Авsтract: Present study analyzes the significance of the scientific publication about the benefits of marine weather for the healing of several childhood diseases. The practical 
implementation of water and the marine environment took place in children's sanatoriums and floating schools ships. The first center was set up in England, expanding to throughout the nineteenth century and the first third of the twentieth century around Europe and America. France, Italy and Germany stood out to introduce a large network of schools ships for the weakest children. This treatment was received by the sickest children or more predisposed from the lower social classes. The aim of reducing the high rates of child mortality and improve the health of poor children was reached effectively and gradually. The combination to manage health and educational activities to the patients admitted was materialized in the fulfillment of a schedule, on the learning of a set of hygienic standards, assorted games, baths, storybook reading and rudimentary teaching of the deed and reading.

Keywords: hygiene, children, sanatoriums, childhood, education.

\section{INTRODUCCIÓN}

"Cultura es lo que queda cuando se olvida todo lo que se aprendió»"

La influencia positiva que ejerce para la salud el consumo y utilización del agua en sus diversas formas y manifestaciones está reconocida en todos los ámbitos, esferas y estamentos. En la actualidad son muy conocidos y anunciados, en distintos medios de comunicación, los famosos balnearios bajo la denominación de Spa. En ellos, el agua se administra a los cuerpos en desiguales formas, tamańos y presiones, proclamándose a bombo y platillo que dicha terapéutica produce en las mentes y cuerpos: paz, bienestar y relajación. Además, se ofrecen diversas terapias en función de las dolencias padecidas por los usuarios y expertos en la materia asesoran sobre el mejor uso de los diversos tratamientos.

Por otra parte, desde hace más de 20 años en los planes de turismo social para nuestros mayores que presenta todos los años el IMSERSO, dependiente del Ministerio de Sanidad, Servicios Sociales e Igualdad, aparece una amplia gama de servicios en balnearios a unos precios reducidos; preconizando múltiples mejoras en enfermedades y padecimientos a través de la utilización del agua combinada con masajes u otras técnicas innovadoras.

Lo anterior nos informa de unas terapias conocidas públicamente como saludables, donde intervienen médicos, fisioterapeutas, masajistas y otros especialistas en la materia.

Selma Ottilia Lovisa Lagertot (1858-1940) fue una maestra y notable escritora sueca, autora de El cuento de una casa de campo señorial (1899) y otras muchas obras. Fue una excepcional contadora de cuentos, mezclando los mitos y las fantasías con un realismo con rasgos moralistas: bondad, amor y el trabajo bien hecho son los poderes más importantes del mundo. Fue la primera doctora sueca honoris causa en filosofía. Primera mujer en obtener el Premio Nobel de Literatura en 1909 y miembro de la Academia Sueca en 1914. 
Un sinfín de balnearios y centros de salud se diseminan por toda nuestra geografía con unos éxitos de asistencia y beneficios económicos muy importantes. Sin embargo, estos tratamientos no son ninguna novedad ya que, como veremos más adelante, son antiquísimos y provienen de la antigua Grecia. Además, las características específicas del agua marina han sido utilizadas en todas las culturas, siendo reconocidos sus beneficios para un sinfín de enfermedades.

Antes de iniciar el desarrollo del estudio que hemos llevado a cabo, es necesario realizar una aclaración en el ámbito conceptual. La mera lectura del título nos puede conducir a prejuzgar que nos introducimos en un artículo dedicado a la medicina. Todo lo contrario, si bien es cierto que el objetivo principal de los sanatorios infantiles era la mejora de la salud de sus ingresados, nuestro enfoque se dirige hacia el estudio y análisis del nacimiento y expansión de estos centros y la acción pedagógica, tanto intencional como no, que se implementaba en ellos. El abordar un tema hasta ahora inexplorado en el contexto educativo, nos debe conducir hacia una reflexión profunda sobre el modo y forma en que nos enfrentamos a la educación actual de nuestros hijos.

Es cierto que los estímulos que se desarrollan fuera del ámbito educativo formal nos procuran elementos formativos únicos que si son asimilados de forma libre y consciente en nuestra estructura de conocimiento, nos procurarán una mayor y mejor adaptación a los aprendizajes actuales y futuros. En esta línea de acción se dirige la aspiración de la sociedad actual y que la plasmamos como: la búsqueda de la formación integral de las nuevas generaciones, aprovechando todos los medios y contextos posibles. La educación social nos brinda esa oportunidad al presentar los elementos necesarios para desarrollar programas pedagógicos ambiciosos desde ámbitos más abiertos, flexibles, dinámicos y cercanos a la realidad de cada momento y sujeto determinado. En la línea descrita, presentamos esta investigación en la que analizamos la fundación de los primeros sanatorios infantiles fuera de nuestras fronteras y su espectacular desarrollo durante todo el siglo XIX y primeros años del XX. Incluimos en nuestro análisis una institución novedosa y no investigada hasta el momento: los sanatorios escuelas flotantes. Los centros sanitarios marítimos para niños enfermizos fueron claros precursores de las colonias escolares. No obstante, esto no fue así en nuestro país, cerca de una década antes de la apertura del primer establecimiento sanitario infantil en España, el Museo Pedagógico de Instrucción primaria, años más tarde Museo Pedagógico Nacional, había fundado de forma oficial las colonias escolares en el verano de $1887^{2}$. Debemos señalar que diversas instituciones públicas y privadas enviaron infinidad de colonias a los sanatorios infantiles. Inclusive, en bastantes de ellas los escolares estuvieron acompañados por maestros, desarrollándose con ellos programas educativos novedosos.

MUSEO PEDAGÓGICO DE INSTRUCCIÓN PRIMARIA: La primera colonia escolar de Madrid (1887), Madrid, Est. Tip. de Fortanet, 1888. 


\section{ANÁLISIS CONTEXTUAL}

El desarrollo de la sociedad industrial en detrimento de la rural, durante todo el siglo XIX y parte del XX, provocó no sólo profundas consecuencias económicas y políticas, sino otras más importantes en todo el entramado social. El nuevo modelo de vida se asoció al crecimiento rápido de la población de las grandes ciudades. El hacinamiento, la mala alimentación y la pobreza de muchos habitantes de las ciudades estaban servidos. Los niños y niñas como los más vulnerables por su edad, fueron los que más soportaron las consecuencias de este cambio social.

Es necesario señalar que la infancia de los sectores más humildes estaba determinada desde su nacimiento por un conjunto de situaciones adversas generadas por el medio familiar, económico, urbanístico y sanitario. El escenario se agravaba con la incorporación temprana al trabajo, el abandono de cientos de niños y la práctica de la mendicidad. En un país donde cerca del ochenta por cien de la población vivía sumida en la pobreza, no era de extrañar las estrategias que desarrollaban las familias para poder sobrevivir ${ }^{3}$. Los datos sobre la mortalidad infantil en los últimos años del siglo XIX en España, se habían disparado hasta alcanzar el 50\% hasta los 6-7 años. Además a comienzos del XX, el índice se había situado en un preocupante $20 \%$ en el primer año de vida 4 .

En el resto de Europa se producía una situación similar, aunque con unas cifras más reducidas en el número de defunciones. Frente a ello, nació en nuestro continente un movimiento en favor de la higiene y la salud de los más necesitados ${ }^{5}$. El centro de interés se iba a concretar en la erradicación de los focos potencialmente infecciosos: viviendas en los barrios pobres de las ciudades, centros de trabajo de las clases populares, colegios y los centros públicos de reuniones. La escuela iba ser utilizada como lugar privilegiado de intervención de los higienistas y los sanatorios infantiles como centros de tratamiento para paliar las enfermedades o predisposiciones a ellas. El objetivo era combatir los múltiples padecimientos producidos por las malas condiciones de vida y contrarrestar los efectos desfavorables que provocaba el progreso económico.

Las obras benéficas denominadas sanatorios de montaña y hospitales marinos se presentaban como redentoras de la infancia humilde y abandonada. A los establecimientos

3 RAMOS VARO, Ma. L.: La protección legal de la infancia en España. Orígenes y aplicación en Madrid (1900-1914), Madrid, Consejo Económico y Social, 2001, pp. 339-340.

4 PONCE DE LEÓN, P.: «La mortalidad de los niños. Conclusión», Boletín de la Sociedad Protectora de los Niños, 39 (1884), pp. 39-46; PENAA MIKELAREINA, F. y GARCÍA-SANZ MARCOTEGUI, A.: «Demografía histórica (siglos XIX y XX)», Historia Contemporánea, 12 (1995), pp. 309-338.

5 TERRÓN BAÑUEÑOS, A.: «La higiene escolar: un campo de conocimiento disputado», Áreas, 20 (2000), pp. 73-94; PONCE DE LEÓN, P.: «La mortalidad de los niños», Boletín de la Sociedad Protectora de los Niños, 37 (1884), pp. 4-6. 
ubicados en zonas costeras iban a ser enviados los nińos pobres que presentaban deficiencias físicas para que, a través de la benéfica acción de los baños de mar y la influencia de las brisas marinas, pudieran reestablecerse de sus múltiples dolencias.

Los primeros centros se calificaron en función del objetivo específico que pretendían, así aparecieron las siguientes denominaciones: sanatorios marítimos, preventorios, escuelas flotantes, hospicios marinos, escuelas sanatorios y casas de curación. Diferían entre sí en algunos detalles, en cuanto a las normas de admisión y organización. De esta forma, unos eran temporales, otros permanentes, unos dedicados a niños enfermos, otros a los predispuestos o débiles y algunos a ambos casos. En todos ellos se coincidía en un punto fundamental: el empleo de los recursos terapéuticos que ofrecía el clima marítimo y el agua de mar como base del tratamiento al que debían ser sometidos los nińos.

\section{LA CURA MARINA FUERA DE NUESTRAS FRONTERAS}

\subsection{Primeras experiencias}

El reconocimiento de las bondades de la vida marina había sido señalado, reiteradamente por afamados doctores, como una modalidad de régimen dirigido a los nińos debilitados por una enfermedad, por la forma de vida en las ciudades o por causas hereditarias. La benéfica influencia para la salud de las aguas y brisas marinas ya se conocía en la antigua Grecia. En aquella época era habitual la utilización de los baños de mar y se empleaba el agua de mar bebida, no desconociéndose la eficacia del aire marino, llegando inclusive a utilizar el agua salina como purgante. A los espacios acotados para su uso se les denominaba arenaria o heliosis ${ }^{6}$. Herodoto, Hipócrates, Galeno y Aureliano recomendaban esta terapia para aliviar diversas enfermedades.

Los romanos usaban los baños de sol, helioterapia, y de lodos no sólo como medio terapéutico, sino más bien como medida higiénica, utilizando unas zonas delimitadas a tal fin llamadas solarium. Asimismo, los árabes fueron partidarios de los baños de sol, destacándose entre ellos Avicena ${ }^{7}$. El agua como fuente de vida ha sido reseñada en multitud de obras. En algunas de ellas, inclusive se ha llegado a afirmar que los baños eran los que: «hacían a los antiguos Celtas, a los Germanos y a los Lacedemonios tan vigorosos» ${ }^{8}$.

6 BROCHARD, A. T.: Del uso de los baños de mar en los niños, Madrid, Administración de la Revista de Medicina y Cirugía prácticas, 1893.

7 JIMENÉZ GINER, R. y ZAMARRIEGO, F.: Guía de la madre y de la enfermera para el cuidado del niño sano y enfermo. Lecciones de puericultura y pediatría, Madrid, M. Aguilar, 1943, p. 163.

8 DE BUSTOS y ANGULO, V.: Baños de rio, caseros y de mar, Madrid, Imp. de Villapando, 1816, p. 25 . 
Expresión bastante exagerada pero que nos confirma el importante valor con que era tratada la utilización del agua.

Las primeras noticias escritas sobre el valor medicinal de las aguas de mar que, más tarde tuvieron una gran repercusión en el entorno europeo, se remontan a mediados del siglo XVIII. En concreto en 1750, con la publicación en latín en la ciudad de Oxford de la obra del médico inglés Richard Russell: De tabe glandurari, sirve de uso aqua marina in morbis glandularum 9 . Traducida al castellano como El uso del agua de mar en las enfermedades de las glándulas. Russell observó que los niños que habitaban en las zonas de costa tenían en general mejor salud que los de las ciudades. Por tal circunstancia recomendaba los baños de mar e inclusive la ingesta de agua marina. Desde la aparición y difusión del citado libro, la talasoterapia ${ }^{10}$ o terapéutica marina cobraron importancia y se revelaron como medios eficaces para tratar con éxito a los escolares enfermos y/o afectados de pobreza vital o miseria fisiológica, adquiriendo el carácter científico. Si ańadimos a esto que en los inicios de la segunda mitad del siglo XIX, el escrofulismo, el raquitismo y la tuberculosis se demostraban como enfermedades aterradoras en todos los países europeos, la fundación de sanatorios marinos para niños pobres se presentaba como una solución ante la imperiosa necesidad de luchar y prevenir los males que acechaban y padecían cientos de miles de niños. En sus orígenes y en la mayoría de los casos, el carácter de estos establecimientos se circunscribía a la obtención de objetivos higiénicos y terapéuticos.

El honor de ser el primero en fundar la obra sanatorial benéfica, se le debe anotar al doctor inglés Latham, quien influido por las ideas de Russell, propuso en 1791 la fundación de un hospital marino. La idea fue muy bien acogida y con el producto de una suscripción popular abierta al efecto, se construyó en la desembocadura del Támesis el Hospital marítimo de Margate, a pocos kilómetros de la capital, Londres, y bajo el nombre de: Royal sea Bathing Infirmary». El establecimiento fue inaugurado en 1796 por el Príncipe de Gales y estuvo dirigido en sus inicios por el médico Lettsom ${ }^{11}$. A las personas que se distinguían con su participación económica en el sostenimiento de este centro u otros de similares características, se les concedía el título honorífico de Gobernors, distinción muy

LOSTE ECHETO, L.: Los sanatorios maritimos para niños escrofulosos y el doctor Tolosa Latour, Huesca, Tip. Viuda de L. Pérez, 1920, p. 15. En la obra de BROCHARD, A. D.: Del uso de los baños..., op. cit., 1893, p. 22, aparece la referencia del libro de R. Russell con la fecha de 1550 cuando en otras publicaciones se afirma que fue en 1750 .

10 La Talasoterapia es una tipología de tratamiento basada en la utilización de los diferentes medios marinos, agua de mar, algas, barro y otras sustancias extraídas del mar y del clima marino como agentes terapéuticos. Los resultados en la curación de la escrófula, raquitismo y tuberculosis a través de la acción de la atmósfera y agua de mar fueron muy importantes; vid. ASOCIACIÓN NACIONAL PARA LA FUNDACION DE SANATORIOS Y HOSPICIOS MARINOS EN ESPANAA: Sanatorio maritimo de Santa Clara para niños escrofulosos y raquíticos, Madrid, Publicaciones a beneficio del Sanatorio, 1905?.

11 LOSTE ECHETO, L.: op., cit., 1920, pp. 26-27. 
estimada en su momento. En poco tiempo, se fueron construyendo en el Reino Unido otros centros infantiles sanitarios, llegando a 30 hospitales en 1889, bajo la misma modalidad que el de Margate.

El segundo país en orden cronológico en sumarse a la corriente sanitaria fue Alemania. El doctor Lichtemberg conocedor de las prácticas en Margate, fundó un establecimiento balneario de índole similar a mediados del siglo XIX ${ }^{12}$. En esta nación, se habilitó un amplio sistema de sanatorios infantiles dedicados a los niños escrofulosos y predispuestos a la tuberculosis. Destacaron como centros permanentes: el Nordsse Schul-sanatorium con capacidad para 200 camas y el de Norderney construido en el año 1884. Por otra parte, la Asociación para la creación de hospicios marinos para niños enfermos sostenía varios centros, uno en la Isla de Fohr fundado en 1880 y otro cerca de Ribnitz e inaugurado en 1881. Además, en esta misma época se pusieron en funcionamiento otros muchos. En los primeros años del siglo XX, existían en el país teutón cerca de 80 sanatorios infantiles ${ }^{13}$.

\subsection{Una gran expansión en NUestro país vecino. Francia}

El movimiento iniciado en Inglaterra fue secundado con gran entusiasmo por nuestro país vecino. Una institución que impulsó la institución de los sanatorios infantiles fue la Academia de Medicina, fundada a principios del siglo XIX, divulgando con entusiasmo los principios sanitarios e higiénicos de las aguas marinas ${ }^{14}$. Por estos mismos años, la benefactora gala Coraly Kinsh instauró la institución de los hospicios marinos en 1847, fundando el centro de Hinh-Krüger en la ciudad de Cette. Desde el año de su nacimiento y hasta 1878 , se asistió en dicho lugar a 9.000 niños de ambos sexos ${ }^{15}$.

Los avances médicos del siglo XIX, concluyeron que no todos los nińos enfermizos estaban indicados para la cura marina. El aire marino tiene una mayor proporción de oxígeno y por lo tanto menor de ácido carbónico, además contiene numerosas partículas de cloruro sódico que no sólo estimulan el aparato respiratorio, sino la piel a la cual fortifican. El niño de la ciudad no experimentaba el influjo positivo del clima marino, hasta haber transcurrido un período de aclimatación de quince días. Por ello, los niños que se beneficiaban más de esta terapia debían ser los que padeciesen infartos glaglionares, axilares,

12 LOZANO, P.: «Asilos marítimos para niños», Boletín de la Sociedad Protectora de los Niños, 101 (1889), pp. 184-186.

13 LOSTE ECHETO, L.: op., cit., 1920, p. 37.

14 CELADA PERANDONES, P.: «Tres calas en una institución complementaria de la escuela: las colonias escolares leonesas (1895, 1896 y 1936)», Tierras de León, 114 (2002), pp. 105-142.

15 TORRES MARTÍNEZ, J. R.: «Los hospicios marinos en España. Dos palabras sobre dos proyectos", La madre y el niño, II (1883), pp. 25-27. 
cervicales, inguinales o peri-bronquiales y los que tuvieran cicatrices tuberculosas curadas o todos los tuberculosos antiguos. El sanatorio de montańa estaba indicado para aquellos niños que necesitaban una excitación moderada o una gimnasia respiratoria poco activa, además de los nerviosos, herpéticos y artríticos. El centro en altura debía ubicarse entre las altitudes de 700 a 1000 metros $^{16}$. A mayor altura, se había comprobado la existencia de un período de aclimatación que a veces se acompañaba con brotes congestivos que podían constituir un peligro para el nińo

No obstante, debido a los resultados tan exitosos alcanzados en los centros médicos marinos, la asistencia pública de París costeó la creación del Hospital de Berck-surMer. Asimismo, se habilitaron otros muchos por las costas francesas, merecen especial mención el Sanatorio de Arcachón, ideado por el doctor Armengual en el año 1892; Sanatorio de Santa Elena, fundado en 1889 en la playa de Cap-Bretón; Sanatorio de Banyuls-sur-Mer y el Sanatorio de Saint-trojan inaugurados ambos en 1888, cercano el primero a la frontera española. El edificado en Giens y próximo a la localidad de Lyon, se denominó René Sabrán. La beneficencia pública no permanecería al margen e inauguró el Hospital de Hendaya. En este establecimiento se admitía a niños de 3 a 5 ańos y sus puertas estaban abiertas durante todo el año ${ }^{17}$.

\subsection{Un divulgador italiano de la terapéutica marina: G. Barellai}

En la misma línea de otros países, Italia se unió de forma intensa a la corriente higiénica profiláctica. Gracias a la iniciativa emprendida por el doctor florentino, G. Barellai, se posibilitó la fundación de centros marinos en su nación. El facultativo percatado de la influencia positiva que ejercía el agua del mar y sus brisas en las enfermedades escrofulosas ${ }^{18}$ presentó, en el año 1851 a la Academia de Medicina italiana, un cuadro de dos niños que habían fallecido de tuberculosis abdominal en el Hospital de Santa María Nueva de Florencia. En aquella reunión, se preguntaba el médico italiano ¿si se podría haber salvado sus vidas de haberles enviado a orillas del mar? Las pinturas de gran efecto patético, contribuyeron a que gran número de doctores apoyaran la idea de llevar a los infantiles raquíticos y escrofulosos a establecimientos construidos a tal fin. Éstos se ubicarían en las costas del Mediterráneo o del Adriático ${ }^{19}$.

16 RUEDA GONZÁLEZ, M.: Las colonias escolares y las escuelas al aire libre en su aplicación al mejoramiento de la salud y de la enseñanza primaria, Palma de Mallorca, Imp. de Rotger, 1915, pp. 28-29.

17 LOSTE ECHETO, L.: op., cit., 1920, pp. 34-37.

18 TORRES CAMPOS, R.: «La beneficencia marina», Boletín de la Institución Libre de Enseñanza (B.I.L.E.), 167 (1884), pp. 21-22.

19 TOLOSA LATOUR, M.: Los sanatorios maritimos y el Sanatorio de Santa Clara en Chipiona (Cádiz), Madrid. M. Romero Impresor, 1904, p. I. 
En el verano de 1856, G. Barellai y otros doctores trasladaron a tres niños pobres y afectados de escrofulismo a recuperarse a la costa. El empeño se llevó a cabo gracias a la ayuda de la caridad privada y la aristocracia toscana, prescindiendo de toda intervención y apoyo del Estado. El éxito fue increíble, al año siguiente el número de atendidos se multiplicó por dos y a los cinco años ya fueron 66 los participantes ${ }^{20}$. Por fin, se fundó formalmente en el año 1861 en la costa mediterránea el Hospicio marino de Vía Reggio, asistiendo en dicha temporada a 102 nińos con unos resultados excelentes en cuanto a su mejoría médica. Al efecto se creó un organismo directivo formado por representantes de la clase social más elevada, el comercio, la industria, las artes y la medicina. La asociación tenía por objeto dedicar todos sus esfuerzos en la búsqueda de recursos económicos en pro de los infantiles pobres y enfermizos recogidos en los centros habilitados al efecto.

En escaso espacio de tiempo y con el esfuerzo incansable de Barellai y otros médicos, se divulgó y propagó la idea por toda Italia y otros países vecinos como Austria. Las donaciones privadas aumentaron considerablemente y se construyeron establecimientos por todo el país transalpino. De esta forma en 1862, se estableció en Milán el Comité Lombardo, instalando un centro sanitario en las playas de Voltri; en 1862, se fundó un Comité en Modena con el mismo objetivo para la provincia de la Emilia, construyendo el Hospital de Yano a orillas del mar Adriático; en 1864, surgió el Comité de Bolonia; en 1867 los de Pavia, Bergamo, Como, Lodi y de Linborna; en 1868, iniciaron sus trabajos los de Mantua, Brescia, Venecia, Romagna y Roma y en 1871, se fundó el Comité de Turín, levantando los cimientos del Hospital de Loano ${ }^{21}$.

El ascenso del número de hospitales marítimos en Italia fue espectacular. En el año 1883, permanecían en funcionamiento 16 centros. Desde sus inicios, habían recibido tratamiento más de 15.000 nińos de ambos sexos ${ }^{22}$. Los resultados obtenidos fueron indudables, se proporcionó una mejoría sensible en muchos de los ingresados y se redujo notablemente la tasa global de defunción infantil.

\subsection{EXPANSIÓn POR Europa y AmÉrica}

Los éxitos alcanzados en el restablecimiento físico de los escolares más desvalidos, al trasladarlos por unos meses a orillas del mar, provocó que se fundaran otros centros de similares características en el resto de países europeos. En 1883, Bélgica inauguró su

20 TOLOSA LATOUR, M.: «Olas y brisas. Impresiones de un viaje a los sanatorios marítimos de Francia e Italia», en AA. VV.: Biblioteca de vida maritima, Madrid, Imp. Alemana, 1907-1908, pp. 1- 96, referencia en p. 87.

21 TORRES MARTÍNEZ, J. R.: «Los hospicios marinos en...», op. cit., 1883, p. 26-27.

22 TOlOSA LATOUR, M.: Organización de los hospitales de niños, Madrid, Enrique Teodoro Impresor, 1883, pp. 13-14. 
primer centro en Wenduque, cerca de Ostende por iniciativa del doctor Vandenabeele. En Dinamarca se realizó la misma operación en el año 1875, ubicándose en la isla de Seeland a $60 \mathrm{Kms}$. de Copenhague. Otros países como Austria, Hungría y Holanda efectuaron lo propio. Portugal se sumó a la corriente fundando tres hospitales marinos infantiles a finales del siglo XIX ${ }^{23}$.

Rusia inauguró el primer sanatorio para niños convalecientes, anémicos y escrofulosos en 1872, denominado como Oranienbaum. La idea surgió gracias al interés de la gran duquesa Catalina Michailowna. Nueve años más tarde, la caridad privada estableció un sanatorio en Pargalovo, localidad cercana a San Petersburgo. Años más tarde, se fundó la Sociedad de Seguros para niños enfermos de Kieff. También, destacó en la misma línea la obra filantrópica de E. Trepew para establecer sanatorios en Wiatka, Zitomir y en Kieff' ${ }^{24}$.

La empresa traspasó las fronteras europeas, alcanzando a Estados Unidos. En Atlantic City se estableció en 1873 un centro denominado Children's sea-shore house ${ }^{25}$. Este sanatorio fue fundado y administrado por la Junta Caritativa de Filadelfia, estando consagrado al tratamiento de enfermedades crónicas de la infancia y admitiendo nińos escrofulosos, si bien no se dedicaba exclusivamente a este régimen. Asimismo, en los países más importantes de América del Sur, se fundaron otros establecimientos en las mismas condiciones. En el año 1876, inició sus actividades uno en las cercanías de Montevideo. También Argentina se sumó a la corriente inaugurando el Asilo Sanatorio Mar del Plata en 1893. Ubicado a $400 \mathrm{Kms}$. de Buenos Aires, su instalación se debió a los esfuerzos de la Sociedad de Beneficencia de Buenos Aires. Aceptaba a los niños pobres de las clases populares bajo dos modalidades. La primera dedicada a enfermos tuberculosos y una dedicada a niños débiles, enfermizos o propensos a enfermar ${ }^{26}$. Como curiosidad debemos señalar que en los países sudamericanos a estas instituciones se las denominaba también: escuelas preventivas de mar para niños débiles.

Más tarde, fue aumentando el número de sanatorios y la cifra de niños y niñas atendidos. Una nota dominante fue la labor de defensa y propagación de esta institución benéfica por médicos, higienistas, maestros y personas amantes de la infancia. La campaña en favor de la mejora de salud de los niños pobres, tuvo unos resultados importantes pero algo lentos. En el orden económico, la realización y puesta en práctica de estos

23 LOSTE ECHETO, L.: Los sanatorios maritimos..., op. cit., 1920, pp. 34-37.

24 ZARNITZKY, A. O.: «Los sanatorios infantiles», Boletín de la Sociedad Protectora de los Niños, 248 (1901), pp. 6-8.

25 RUEDA GONZÁLEZ, M.: Las colonias escolares y las escuelas al aire libre..., 1915, p. 14.

26 ÁLVAREZ, A.: «La experiencia de ser un niño débil y enfermo lejos de su hogar: el caso del Asilo marítimo, Mar del Plata (1893-1920)», Història, Ciências, Saúde-Manguinhos, vol. 17, 1 (2010), pp. 13-31. 
centros, se debió a las múltiples donaciones y suscripciones privadas que se realizaron, destacándose la aristocracia del momento y la nueva burguesía aparecida con los nuevos cambios industriales y sociales que se experimentaron por toda Europa. Más tarde y debido al éxito obtenido, los poderes públicos fueron tomando conciencia del beneficio que reportaba la institución marina. Desde formulaciones diversas, instituciones públicas estatales, cantonales, regionales y municipales se fueron sumando al movimiento sanatorial infantil durante todo el siglo XX.

\section{LOS SANATORIOS ESCUELAS FLOTANTES}

Tomando la idea de la cura marina como fórmula de mejora sanitaria, nació en Inglaterra a finales del siglo XIX la experiencia innovadora de las escuelas sanatorios flotantes para niños enfermos. El buque Goliat fue habilitado por el gobierno inglés para el acogimiento y educación de niños enfermos o predispuestos a ello. Desaparecido éste por un incendio en el año 1882, fue sustituido por otro con el nombre de Exmontch. El objetivo era educar y hacer ciudadanos útiles a los escolares desamparados y enfermizos, con la utilización de los influjos de la vida marina. Se tiene constancia documental que en Espańa, gracias a un grupo de personas filantrópicas que lo sostenían económicamente, funcionó durante unos años como escuela hospital flotante la corbeta Mazarredo ${ }^{27}$.

La metodología de escuela sanatorio en embarcaciones fue ensayada con éxito en algunos países como Estados Unidos. Esta nación destacó en la habilitación de grandes navíos para escuelas flotantes. Los responsables educativos y sanitarios conocedores de las experiencias europeas realizadas con éxito, iniciaron las primeras aplicaciones prácticas en 1894. Por medio de pequeñas embarcaciones se organizaron excursiones experimentales con una decena de niños y varios sanitarios y maestros. El método era bien sencillo, una barcaza recogía por la mañana en un puerto a la tripulación y a un grupo de niños previamente seleccionados y realizaba una travesía marítima para retornar al mismo lugar y desembarcar a los niños que pasaban la noche en sus domicilios ${ }^{28}$.

Los resultados tan excelentes de los paseos marítimos infantiles en cuanto a la mejora de la salud y enseñanza de los participantes, promovieron que se construyeran navíos exclusivamente para tal finalidad. En 1906, en la ciudad de Boston se puso en funcionamiento el Boston Floating Hospital, un barco de 594 toneladas, 165 pies de eslora, 45 de manga y 10 de calado. La admisión se reservada a nińos menores de seis años que requerían asistencia médica. Además, en él se admitía a las madres o personas encargadas de los pequeños. La acción beneficiosa para los escolares se completaba con

27 Boletín de la Sociedad Protectora de los Niños, 19 (1882), p. 112; «Revista extranjera», Boletín de la Sociedad Protectora de los Niños, 20 (1882), p. 127.

28 REDONDO, J.: «Sanatorios flotantes», Vida maritima, 246 (1908), pp. 471-472. 
instrucciones educativas a las madres sobre los cuidados higiénicos, señalando a la falta de estas atenciones como las responsables de la elevada mortalidad infantil. El barco disponía de salas amplias, ventiladas y limpias con zonas de baños y desinfección. La cubierta se consagraba enteramente a los niños enfermos permanentes con siete salas para albergar 150 camas. Los laterales se reservaban para los paseos y clases para los niños convalecientes o enfermos. La enseńanza elemental que impartían los docentes adscritos al barco se llevaba a cabo con arreglo a los principios de Fröbel. La farmacia, cocinas, alojamiento de médicos y enfermería completaban las instalaciones. El personal estaba compuesto por el capitán, marineros, doctores, enfermeras y maestros. En el primer año de funcionamiento recibieron asistencia 509 niños permanentes y 900 como asistentes a las excursiones diarias. Especialistas espańoles en la materia, se trasladaron fuera de nuestras fronteras para comprobar los resultados tan importantes que se producían en la mejora de múltiples enfermedades y en la adquisición de conocimientos higiénicos básicos por parte de las madres y niños embarcados ${ }^{29}$.

\section{PLAN DE VIDA EN LOS SANATORIOS}

En general, la vida diaria de los niños enfermizos en los centros sanitarios, tanto terrestres como flotantes, se caracterizaba por el cumplimiento de un horario y por la aceptación de un conjunto de normas básicas que se establecían con anterioridad. Éstas presentaban variaciones específicas según la naturaleza concreta de cada uno de los establecimientos y de sus ingresados. En el Sanatorio de Hendaya, dependiente de la asistencia pública de París, se admitía a niños y niñas anémicos y escrofulosos en primer período, no asistiendo a los enfermos crónicos. Los ingresados eran reclutados en los dispensarios infantiles de la capital gala y lo hacían por orden de la inspección médica escolar.

Desde el momento en que los médicos decidían el ingreso del escolar, se iniciaba el desarrollo de un programa bien organizado, en el que se planificaban las expediciones y resto de actividades. Los viajes en tren se llevaban a cabo en vagones preparados al efecto, acompañados por personal sanitario y procurando que no les faltara de nada a los escolares. El personal facultativo disponía del historial sanitario y de los datos personales de cada uno de los expedicionarios y de sus familias. Al ingresar los niños eran sometidos a las prácticas de lavado higiénico, rapado del cabello y asignación a un pabellón según sexo; permaneciendo entre 15 y 20 días en observación. Con ello, se intentaba evitar la transmisión de cualquier enfermedad que los niños tuvieran en período de incubación. El número de niños y niñas era variable, por lo general cada una de las expediciones constaba de entre 40 y $75^{30}$.

$29 \quad$ Ibidem, p. 472 y La Correspondencia de España, 14.391 (1/07/1897), p. 2.

30 ALONSO DE VELASCO, I.: Colonias escolares y sanatorios maritimos, Madrid, Est. Tip. de José Izquierdo, 1912, p. 27-28. 
La vida de los internos en el Sanatorio de Hendaya se iniciaba a las seis de la mañana, levantándose y realizando su aseo personal con la ayuda del personal sanitario, se incluía el lavabo de boca, nariz y oídos con los utensilios de limpieza asignados y numerados. A continuación, se pasaba a tomar un desayuno nutritivo, reposando una media hora. Más tarde, acompañados por enfermeras se trasladaban a la playa donde tomaban el baño de agua y/o sol, según se disponía en el régimen diario de cada escolar. Además, éstos jugaban en la playa de forma espontánea y a veces en juegos organizados por el personal, los bañeros adscritos al sanatorio cuidaban del buen orden y armonía. Después, se iniciaban las clases divididas por sexos e impartidas por personal docente adecuado. Se intentaba adaptar los conocimientos al nivel educativo de cada niño, formándose grupos homogéneos. La enseñanza de la escritura, lectura y cálculos básicos era el objetivo perseguido. Seguidamente, se pasaba a la comida aislando a los niños y niñas, ya que en dicho hospital no eran partidarios de la coeducación. La alimentación se componía a base de carne y todos los niños tomaban vino en las comidas. Concluido el almuerzo se les permitía reposar y luego se volvía a la playa hasta la hora de la merienda. Concluía el día de los nińos, paseando y jugando entre los pinares cercanos hasta la hora de la cena. Posteriormente, se comunica a todos el momento del acto de silencio y los acogidos ocupaban sus camas para el descanso ${ }^{31}$.

La estancia normal era de tres a cinco meses como mínimo y en la mayoría de ellos se disponía de enfermería, cocinas, gimnasio ortopédico, salas de baños y desinfección y una estancia dedicada específicamente para niños catalogados como infecciosos. Habitualmente el personal de los centros se componía de un médico director, más otros doctores ayudantes residentes internos, enfermeras, personal subalterno y mujeres jóvenes que desempeñaban sus trabajos de forma voluntaria. Los maestros acudían durante un número de horas determinadas o en algunos casos residían en el propio sanatorio.

\section{CONCLUSIONES}

Ciertamente que el principal objetivo perseguido con el establecimiento y desarrollo de los sanatorios marítimos infantiles se consiguió con la mejora en la salud y la reducción paulatina de los altos índices de mortalidad infantil. Si bien, como dato negativo debemos señalar que ocasionalmente se producían casos de contagios de diversas enfermedades debido a la convivencia diaria de los nińos.

La división de los asistentes en dos categorías, enfermos y los predispuestos a enfermar, condicionaba en parte la forma de actuar del personal sanitario y docente. La cura marina y alimenticia de los nińos declarados como enfermos o infecciosos era más intensa y rigurosa, con una reducción del tiempo de las clases que se les impartía. Por lo

$31 \quad$ Ibidem, p. 28. 
general, en todos los sanatorios se contrataba el servicio de maestros que implantaban un programa adaptado a las necesidades concretas de los acogidos. Para los niños débiles o predispuestos a enfermar se disponía de un horario más flexible. La adscripción a una u otra categoría, se realizaba con el diagnóstico de los médicos en función de diversas pruebas. El test de la tuberculina era clave para determinar si el niño estaba infectado o no con el bacilo tuberculoso. El dar positivo en dicha prueba, no significaba que se desarrollaría dicha enfermedad, sin embargo era un indicador que conllevaba la estigmatización futura de los niños.

El seguir día a día un horario establecido, llevar a la práctica un conjunto de normas de aseo y reglas higiénicas, el comer en la mesa bajo unas normas y el interactuar con otros niños en múltiples juegos y baños, provocó un conjunto de nuevos aprendizajes muy importantes para los escolares. Las estancias superiores a los tres meses acompañadas de la administración de una alimentación sana y equilibrada hicieron renacer la salud a miles de niños.

Las enseñanzas que se impartían de forma reglada pasaban por los rudimentos de la enseñanza de la lectura, escritura y cálculo. Además en algunos centros, la lectura de cuentos y la realización de pequeñas excursiones engrandecían el mundo de las ideas de los niños. La asistencia de niños en unión a sus madres en los sanatorios flotantes, procuraba inculcar en ellas las reglas higiénicas y de salubridad para el cuidado de los más pequeños, llevándolo a la práctica con sus hijos en las cortas navegaciones. El aire y agua marina fueron verdaderos vivificadores para miles de niños débiles y enfermizos.

Como resumen, podemos afirmar que en la vida diaria de los sanatorios marinos infantiles se desarrollaron de forma brillante los principios higiénicos básicos. Gracias a su puesta en práctica y divulgación, muchas madres aprendieron a cuidar higiénicamente a sus hijos y miles de niños lograron sobrevivir a tremendas enfermedades, otros las superaron o ni tan siquiera las llegaron a contraer. El analizar el desarrollo de los primeros centros sanitarios infantiles marítimos fuera de nuestras fronteras, nos emplaza a efectuar futuras investigaciones que nos permitan identificar de qué forma se enfrentaron los sectores médicos, higiénicos y docentes de nuestro país a las elevadas cifras de mortalidad infantil que se padecían en España. 


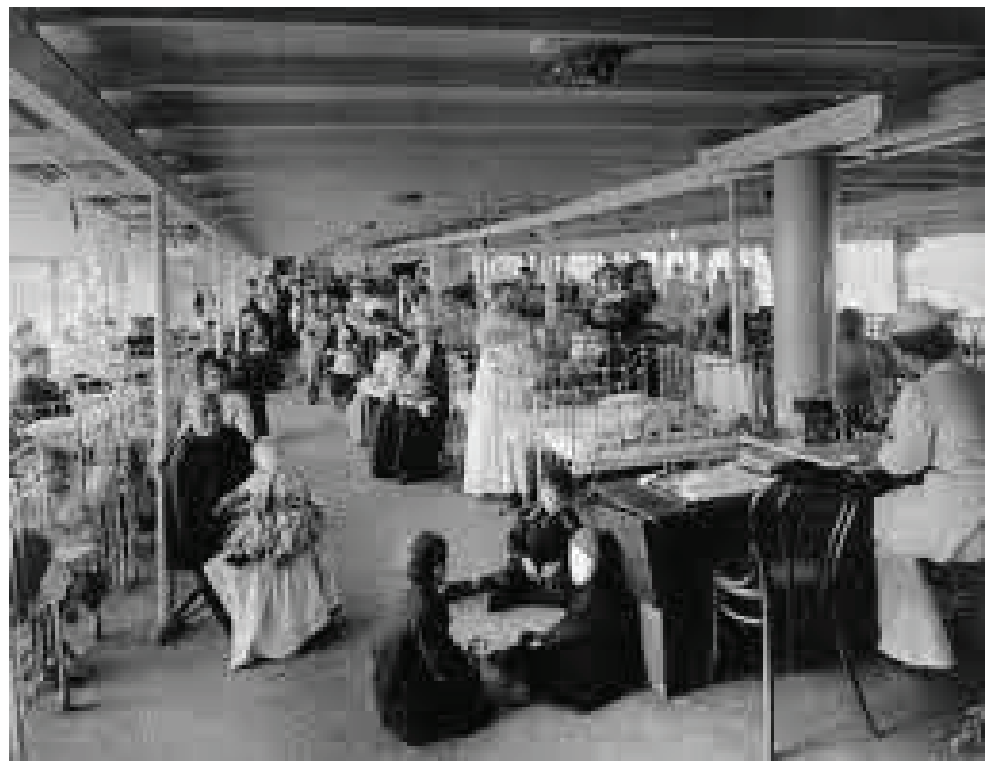

Niños y su madres en la cubierta del hospital escuela flotante Boston. Instantánea tomada de Tufts University, Digital Collection \& Archives, accesible en <http://sites.tufts.edu/ $\mathrm{dca} /$ ?p=all\&pid=114> [consulta: 22-03-2013]
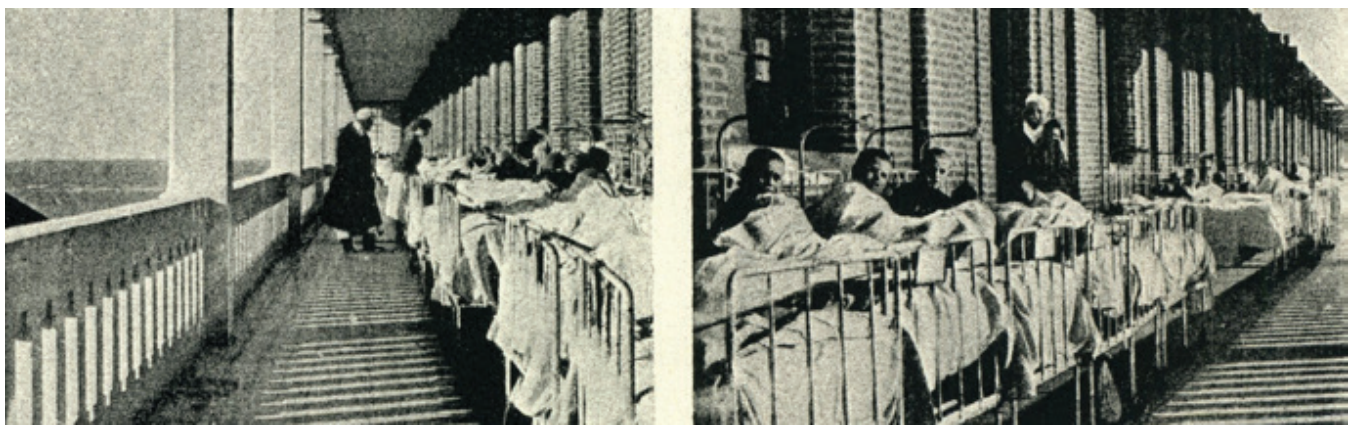

Galerías de insolación de niños en cama en el Sanatorio marítimo de Berk (Francia). SÁNCHEZ SARTO, L. (Dir.): Diccionario de pedagogía, Barcelona, Labor, 1936, p. 2.852. 


\section{Photo \# NH 95893 USS Boston Floating Hospital in port, 1918}

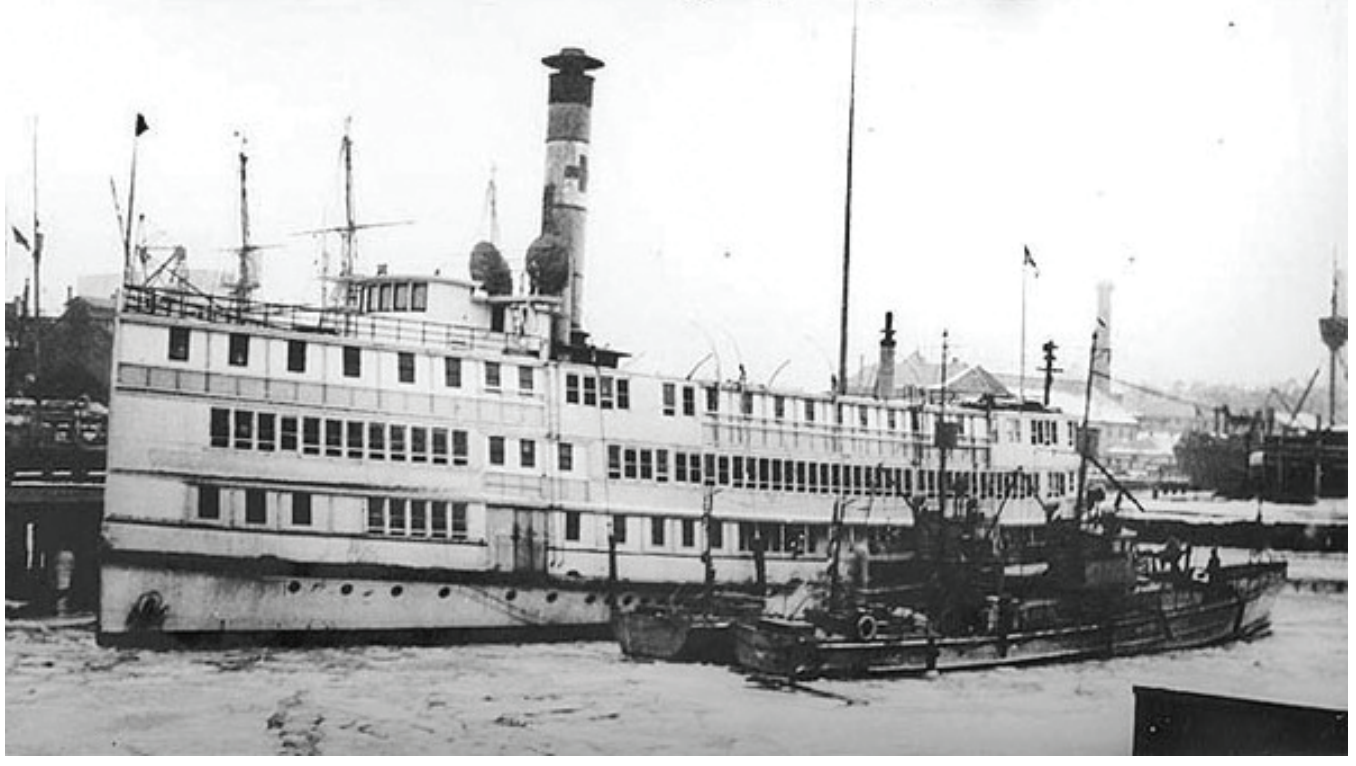

Hospital escuela flotante Boston atracado en un puerto. Es una reproducción de la que aparece en Tufts University, Digital Collection \& Archives, accesible en <http://sites.tufts.edu/ $\mathrm{dca} /$ ?p=all\&pid=114> [consulta: 22-03-2013]. 